\title{
Entrepreneurial identity and role expectations in nascent entrepreneurship
}

\author{
Mats Lundqvist, Karen Williams Middleton and \\ Pamela Nowell
}

\begin{abstract}
Entrepreneurship has been defined as an individuak $\rightarrow$ new value creation dialogic. To study how entrepreneurial identity evolves, this article, drawing on entrepreneurial learning theory, adds an entrepreneurial role expectations dialogic. Longitudinal evidence from nascent entrepreneurs working in venture teams on invention disclosures offers an illustration of dialogics, including how they evolve over time to build entrepreneurial identity. In contrast to the theory of planned behaviour, the findings suggest that becoming entrepreneurial does not stem primarily from intention but rather from interacting with new value creation and role expectations in an immediate team environment.
\end{abstract}

Keywords: becoming entrepreneurial; $k N V V C$ dialogic; identity; nascent; role

Mats Lundqvist is Professor, Karen Williams Middleton is Associate Professor and Pamela Nowell is a PhD student in the Division of Management of Organizational Renewal and Entrepreneurship, Chalmers University of Technology, 41296 Gothenburg, Sweden.

Corresponding author: Karen Williams Middleton. E-mail: karen.williams@ chalmers.se. ${ }^{1}$

This article explores entrepreneurial identity and how it interacts with both new value creation (NVC) and entrepreneurial role expectations over time. In the literature, entrepreneurship is increasingly addressed as a process of emergence (Fisher, 2012; Gartner, 1993; Gartner et al, 1992; Lichtenstein et al, 2006; Tornikoski and Newbert, 2007), emphasizing learning and stages of development (Corbett, 2005), particularly in the nascent phase (Harrison and Leitch, 2005; Rae, 2002).

However, there are few empirical studies of nascent entrepreneurship capturing how the entrepreneurial identity evolves together with the individual's early-stage venture.

Building on an emergent perspective, Bruyat and Julien (2001) presented a definition of entrepreneurship as a dialogic between the individual acting and the new value being created. Dialogic can be understood as embedded interactions within which both learning and creating are possible and change is expected for both the individual and the new value created (Boulding, 1956; Bruyat and Julien, 2001). The 'individual $\leftrightarrow$ new value creation' dialogic ( $\mathrm{I} \leftrightarrow \mathrm{NVC}$ ) is seen as occurring over time in a surrounding environment, having greater or lesser influence on the dialogic (as represented in Figure 1).

In a similar vein, Morris et al urge us to '... move away from an instrumental view (for example, entrepreneurs create ventures and ventures produce outcomes), and allow for the possibility that the venture emerges, in the process developing the entrepreneur' (Morris et al, 2012, p 31). They explain that the entrepreneurial identity of both the individual and the venture being created are constructed and reconstructed during the emergent process, through application of motivation, intention, affective reactions, experiences and expectations (Morris et al, 2012). This suggests a 


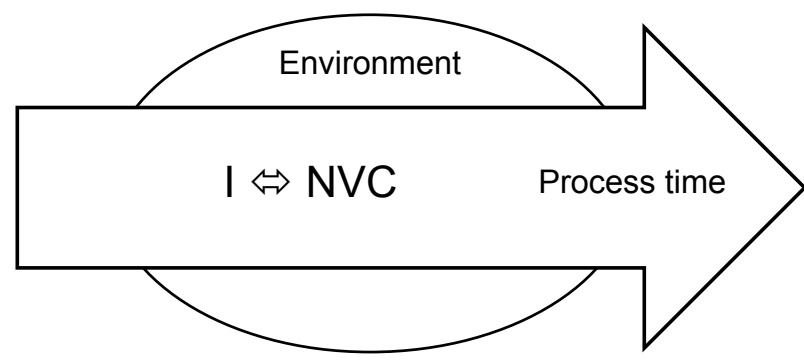

Figure 1. The $\mathrm{H} \leftrightarrow \mathrm{NVC}$ dialogic defining entrepreneurship (from Bruyat and Julien, 2001).

more intricate interaction taking place represented in the $\mathrm{I} \leftrightarrow \mathrm{NVC}$ dialogic. In this article, we address this interaction by introducing the concept of entrepreneurial role expectations (ERE), having its own dialogics with the individual (existent identity) (I↔ERE) as well as with new value creation (ERE $\leftrightarrow \mathrm{NVC}$ ).

Compounded by the methodological challenges of empirically accessing individuals as they engage in entrepreneurial emergence, there is a lack of understanding of the process of becoming entrepreneurial during the nascent phase of entrepreneurship. The aim of this article is to develop and empirically illustrate a framework for understanding emergence of entrepreneurial identity.

We build on the entrepreneurial learning literature emphasizing the embeddedness of the individual becoming entrepreneurial, pointing to the social construction of identity and legitimacy through interactive mechanisms such as narrative, storytelling and negotiation (see, for example, Down and Warren, 2008; Downing, 2005; Pittaway and Thorpe, 2012; Rae, 2005). Social construction of entrepreneurial identity involves a set of key actors, termed initially by Carsrud and Johnson (1989) as a role-set, who advise and position the individual becoming entrepreneurial. In a nascent phase of entrepreneurship, the role-set is regarded as having particular influence on the construction of the entrepreneurial identity (Rigg and O’Dwyer, 2012; Williams Middleton, 2013), supporting our focus on a more immediate (team) environment, in comparison to a more general environment depicted by Bruyat and Julien (2001) (as shown in Figure 1).

In this study, the individuals investigated were engaging in an entrepreneurial process fitting Morris et al's (2012) description of individual and venture identity co-creation, and also representing Bruyat and Julien's I $\leftrightarrow$ NVC dialogic (Bruyat and Julien, 2001). These individuals were considered to be nascent entrepreneurs, where 'nascent' symbolizes both the stage of the venture (early, prior to incorporation) that the individuals are developing, and the level of entrepreneurial experience of the individuals (in other words, a lack of experience in venture creation). These nascent entrepreneurs are also 'surrogate entrepreneurs' (Franklin et al, 2001; Lundqvist, 2014) who assume an entrepreneurial role relative to a technological idea (disclosure of an invention) which does not originate either from themselves or a group with which they are directly associated (such as a working group or a family). Because surrogate entrepreneurs are by definition assigned to take on ideas that others have developed, they lack history with regard to the idea. Most of the students who were surrogate entrepreneurs in this study also lacked previous experience of new ventures. As a result, the type of entrepreneurial identity investigated differentiates from situations such as generational family firms in which there is a lot of history and for which there are direct role-models where the nascent entrepreneur is apprenticed to a family member in the firm - as discussed, for example, in Miller et al (2011); or franchise endeavours, where there are existing models or representations of entrepreneurial action and value creation. Rather, the student surrogate entrepreneurs in this case were embedded in an environment where they were matched with an idea and one or two other nascent entrepreneurs, and surrounded by a set of actors supporting venture development and entrepreneurial action. As such, the empirical setting thus provides for the study of nascent entrepreneurs developing identity from dialogics with the new value being created, and with entrepreneurial role expectations in the immediate (team) environment.

The article proceeds as follows. First, we explore the literature addressing entrepreneurial identity and entrepreneurial role. We then focus more specifically on the nascent entrepreneur (understood as the individual in the process of becoming, and thus constructing, an entrepreneurial identity for the first time), finally producing a conceptual model. Building on the model, we establish a methodology for investigating a venture creation programme, analysing primary and secondary data of nascent (surrogate) entrepreneurs over a nine-month period. We present and discuss our findings, and conclude with suggestions for future areas of study.

\section{Theory}

Bruyat and Julien's (2001) dialogic gives us the subject (the individual) and the object (the new value) around which development toward becoming entrepreneurial occurs. The cognitive development of an individual leading to construction of an entrepreneurial identity is found primarily in literature dealing with entrepreneurship education and entrepreneurial learning (Haynie et al, 2010; Penaluna et al, 2010). In contrast, value creation and development towards identity (or 
legitimacy) as an entrepreneurial firm can be found across multiple literature streams, including nascent entrepreneurship (see, for example, Delmar and Davidsson, 2000; Diochon et al, 2005), entrepreneurial dynamics (see, for example, Gartner et al, 2008; Reynolds, 2007) and new venture processes (see, for example, Shepherd et al, 2000; Shepherd and Haynie, 2009).

While these contributions add aspects to our understanding of the process of becoming entrepreneurial, it is also apparent how complex it is to capture the transformative co-creation of the individual becoming entrepreneurial and the simultaneous value object becoming the entrepreneurial firm; that is, what Bruyat and Julien (2001) call the I $\leftrightarrow$ NVC dialogic (Figure 1).

In the next section we focus on nascent entrepreneurs characterized as not yet having entrepreneurial identity and thus forced to 'act as if' (Gartner et al, 1992, Johannisson, 2011) as they attempt to fulfil the entrepreneurial role.

\section{Entrepreneurial role and entrepreneurial identity}

The understanding of entrepreneurial identity and the entrepreneurial role has evolved from individual traits theory and individual decision-making into something more relational and embedded (see, for example, Aldrich and Zimmer, 1986; Carsrud and Johnson, 1989; De Clercq and Voronov, 2009). In Kilby's 'Hunting the Heffalump' (Kilby, 1971), the entrepreneurial role is reduced to decision-making under conditions of uncertainty. Kilby (1971) and Gartner (1988) set the ground for emphasizing that it is the actions of the individual rather than individual characteristics which define someone as being entrepreneurial. However, the role of the entrepreneur is also portrayed symbolically, through myth and metaphor (Anderson, 2005; Anderson and Warren, 2011; Down and Warren, 2008;

Drakopoulou Dodd and Anderson, 2007; Nicholson and Anderson, 2005). It is shaped by the literature and culture of both business and popular science and can be understood as a distinct from other roles and identities (Murnieks and Mosakowski, 2007). Beyond an instrumental view of 'you are what you do', there are more relationally oriented understandings of what it is to be either an entrepreneur or entrepreneurial. The individual factor of role can be considered the static equivalent of the negotiated rights and duties determined through positioning (Davies and Harré, 1990). Terms identified as titles are used to communicate a role or position, such as leader, manager, business developer or entrepreneur.

Rigg and O'Dwyer (2012) offer a description of becoming entrepreneurial as joining a community of practice, facilitated mainly through social interaction. This understanding of entrepreneurial identity is reflected in the extant literature on entrepreneurial learning. Rae (2006) provides a triadic model of entrepreneurial learning, emphasizing an individual's competence in acting 'as the entrepreneur' developed through contextualization, personal and social emergence, and negotiated experience. In this model, Rae summarizes the work of Cope and Watts (2000), Gibb (2002), Weick (1995), Wenger (1998), and many others, in order to build on the ways in which we recognize that experiential and situated learning processes, network and industry socialization, and negotiation lead to recognition as having fulfilled the role 'entrepreneur' and, as such, having acquired an entrepreneurial identity. Rae's triadic model of entrepreneurial learning provides a useful contrast to an understanding of becoming entrepreneurial that is based upon the theory of planned behaviour (Ajzen, 1991). Applying an entrepreneurial learning perspective, rather than a theory of planned behaviour understanding, to for example - entrepreneurship education implies that intention is not sufficient in order to become entrepreneurial. There also needs to be a context in which to engage entrepreneurially. The contrast is captured in the expressions 'education about' or 'education for' entrepreneurship (applying theory of planned behaviour) as opposed to 'education through' entrepreneurship (Gibb, 2011; Neck and Greene, 2011; Williams Middleton and Donnellon, 2014).

Scholars of identity emphasize the importance of differentiating identity from role: identity is specific to each individual as a set of self-conceptualized meanings that relate to a socially constructed role (Gecas, 1982; Hytti, 2003), whereas a role is a concept used to represent expected behaviours attached to a social status or position (Cast, 2004; Murnieks and Mosakowski, 2007). Entrepreneurial identity can be assumed somehow to be created through the on-going engagement in the process (including the future incorporation of the venture and beyond) (Donnellon et al, 2014; Pittaway and Thorpe, 2012; Rae, 2005). The entrepreneurial identity is primarily characterized by the individual being positioned (by themself and others) as a key person embodying, communicating, and/or representing the value creation, often seen in the form of a venture (Garud et al, 2014; Rigg and O'Dwyer, 2012; Williams Middleton, 2013). This can be understood as a strong correlation between the individual and the object created, which resonates with Bruyat and Julien's I $\leftrightarrow$ NVC dialogic (2001).

However, nascent entrepreneurs often lack the efficacy associated with experience as an entrepreneur (Dew et al, 2009). They are challenged to construct an 
entrepreneurial identity without experiential knowledge of what that identity entails. We argue here that in lacking the ability to self-conceptualize meaning towards an entrepreneurial identity (due to lack of entrepreneurial experience), the nascent entrepreneur uses entrepreneurial role descriptions (particularly those articulated and appreciated in their immediate environment) to guide expected behaviour.

\section{Entrepreneurial role expectation (ERE) in the nascent phase}

Current mainstream literature concerning nascent entrepreneurship adheres essentially to a functional and instrumental understanding of becoming entrepreneurial: you carry out certain activities and thus you become entrepreneurial. This perspective can be identified in research stemming from the Panel Study of Entrepreneurial Dynamics, and similar studies (see, for example, Davidsson and Reynolds, 2009; Liao and Welsch, 2008; Reynolds, 2007; Robb and Reynolds, 2007), which itemize a set of activities that help to define the nascent phase of entrepreneurship (the process of emergence). In addition, the associated individual carrying out these activities can then be identified as the entrepreneur.

An instrumental understanding of entrepreneurial identity is arguably insufficient. Entrepreneurial activity requires social legitimacy (Clarke and Holt, 2010; De Clercq and Voronov, 2009; Williams Middleton, 2013; $\mathrm{Yu}, 2004)$, and the entrepreneurial role is contingent upon societal influence, because it is an emic construct (Farmer et al, 2011; Schaffer and Riordan, 2003). ${ }^{2}$

Becoming entrepreneurial and taking on an entrepreneurial identity is thus related to 'the extent to which the individual's self-description fits his or her perceptions of the entrepreneurial role' (Farmer et al, 2011, p 2). Establishing a new identity through role-emulation is grounded in the identity literature as establishing 'provisional-selves' when engaging in the process of taking on a new identity in the workplace (Ibarra, 1999; Ibarra and Barbulescu, 2010): the individual wishing to adopt the new identity of (for example) manager, identifies a role model in the workplace while also constructing a new 'transitional' identity that is validated by the social environment in real time.

Establishing 'provisional selves' can be much more challenging for entrepreneurs (and nascent entrepreneurs in particular) because there it is often the case that no organizational form exists with individuals already established in the role one is trying to emulate. ${ }^{3}$ Rather, the entrepreneurial role is a hybrid of a set of functional activities (such as those depicted through Panel Study of Entrepreneurial Development, PSED,

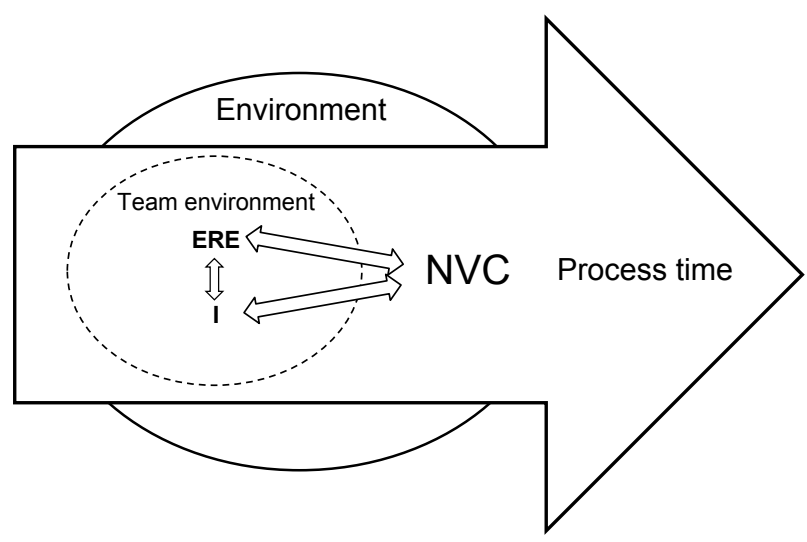

Figure 2. Nascent entrepreneurial dialogic.

and similar studies) and myths and metaphors from society (Drakopoulou Dodd and Anderson, 2007; Nicholson and Anderson, 2005; Ogbor, 2000), as well as expectations and responsibilities defined by the more immediate social setting - such as a team, a community or local industry sector (Carsrud and Johnson, 1989; Williams Middleton, 2010). To address this, we introduce the term 'entrepreneurial role expectation' (ERE), and propose that, particularly for nascent entrepreneurs, there is an I $\leftrightarrow \mathrm{ERE}$ dialogic that contributes to the individual defining their entrepreneurial identity.

Figure 2 illustrates a synthesized understanding of entrepreneurial identity development, building upon the I $\leftrightarrow$ NVC dialogic of Bruyat and Julien (2001) and adding the I $\leftrightarrow$ ERE dialogic, derived above, situated in the immediate (team) environment as well as an ERE $\leftrightarrow$ NVC dialogic. To become entrepreneurial, we propose that nascent entrepreneurs use an intermediating concept - ERE - instead of focusing on entrepreneurial identity, an end result. Entrepreneurial role expectations - 'who I want to become' - are seen to react to, as well as affect, individual identity (I) 'who I am' - resulting in an entrepreneurial identity which is constructed and reconstructed over time. Entrepreneurial role expectations are seen as having dialogic with new value creation, stimulating continuous re-evaluation of both factors. Expanding Bruyat and Julien's dialogic (Figure 1) we thus allow new value creation to interact with entrepreneurial role expectations (ERE) as well as with individual identity. It is argued that EREs explain entrepreneurial identity development over time and thus are a contribution to our understanding of the way in which dialogics can have an effect on becoming entrepreneurial.

Having established a conceptual model of dialogics contributing to entrepreneurial identity development during the nascent phase of entrepreneurial emergence, 
we next explore empirically the entrepreneurial identity development of nascent entrepreneurs. In the Method section, we qualify the empirical setting as representative of entrepreneurial emergence, including new value creation and individuals acting as nascent entrepreneurs. Based upon unique access to a venture creation programme, we investigate how students as nascent entrepreneurs (also acting as surrogates) articulate their entrepreneurial identity as resulting from the I $\leftrightarrow$ ERE dialogic within the immediate environment of their team and associated role-set.

\section{Method}

Given the explorative nature of the study, we used a qualitative, localized and in-depth approach to investigate the relationships between the nascent (surrogate) technology entrepreneurs and their new ventures, and how this associates with the individual becoming entrepreneurial. The research design involved a multiple case, longitudinal study, incorporating insider-action research (Coghlan, 2001) and case study (Yin, 2008) methodologies.

The insider-action approach is recognized as facilitating access to a wide range of information which, due to secrecy, sensitivity, time constraints, trust, articulation, or other contextual factors, would not normally be available to outside researchers (Brannick and Coghlan, 2007; Coghlan, 2007; Coghlan and Brannick, 2005). The case study methodology includes data collected through participative observation, formal and informal interviews and access to team documentation. Being an insider-action researcher (one of the co-authors) or, alternatively, as staff in the incubation environment (two additional co-authors) provided in-depth insight into the emergent process of becoming entrepreneurial through engagement in creating a new venture.

\section{Data collection}

Action-based approaches to entrepreneurship education exist in which students engage in creating real-world ventures (Blenker et al, 2011; Mwasalwiba, 2010; Neck and Greene, 2011; Vanevenhoven, 2013; Winkel, 2013), the more holistic of these being articulated as venture creation programmes (Lackéus and Williams Middleton, 2015), involving integration of entrepreneurial education with local and regional innovation organizations such as incubators and technology transfer offices. It has been proposed elsewhere that venture creation programmes allow students to 'gain knowledge and understanding of what and who is important when attempting to act entrepreneurially, but adds to this, how one's own actions can and perhaps should be carried out in order to achieve the desired effect' (Williams Middleton and Donnellon, 2014, p 7).

Data were collected from a venture creation programme environment (Lackéus and Williams Middleton, 2015) in which students were formed into teams consisting of three members, connected with intellectual property and put in the position of surrogate entrepreneurs developing initial early-stage technologies into viable technology ventures (Lundqvist, 2014). In essence, the students worked on entrepreneurial projects in which the idea had been developed by someone else. This 'someone else' handed over the main responsibilities of taking the idea forward into a potential company to the students. In this instance, the students were also nascent entrepreneurs, because they had no previous experience in new venture creation and engaged in new venture creation within a specialized technology incubator.

An initial population of 27 nascent (surrogate) entrepreneurs, operating in nine teams, was studied over a nine-month period from September 2012 to May 2013: $41 \%$ of the nascent entrepreneurs were women. The students were interviewed twice during the incubation period, in November 2012 and February 2013. In addition to interviews, data about the nascent entrepreneurs were collected through written documentation, including material for team formation and idea selection, and business plans. The team formation and idea selection document was produced individually in May 2012. ${ }^{4}$ In this document the nascent entrepreneur explains his or her own preference for which idea and set of classmates he or she would most like to work with, including supportive reasoning for these preferences. The document also includes a self-description of skills and strengths the nascent entrepreneur brings to each formation. Business plans were developed continually by each team throughout the nine-month period, with formal drafts presented in October 2012 and May 2013. In June 2013, teams had to make the decision either to continue towards intention to incorporate (that is, establish a formal business entity) or to shut down. At that point, seven teams (listed in Table 1) with at least one original team member continued to engage towards intention to incorporate.

In January 2014 we contacted the business advisors of the ventures to obtain an updated status of the ventures and venture teams. Three of the ventures were incorporated or in the process of incorporation, one venture was being terminated, and the final three were still under development towards incorporation (Table 1). Data included in analysis were contingent on venture continuation or incorporation with at least one of the original team members and so data from four ventures 
Table 1. Selected venture status as at January 2014.

\begin{tabular}{|c|c|c|c|}
\hline Venture Alpha & & Terminated & $\begin{array}{l}\text { One is potentially continuing on his own in a } \\
\text { service-oriented start-up. }\end{array}$ \\
\hline Venture Beta & & $\begin{array}{l}\text { Currently under incorporation } \\
\text { process }\end{array}$ & $\begin{array}{l}\text { Recruiting an external CEO (none of the original team } \\
\text { members involved). }\end{array}$ \\
\hline Venture Gamma & Students 1 and 2 & $\begin{array}{l}\text { Currently under incorporation } \\
\text { process }\end{array}$ & $\begin{array}{l}\text { Two of the three original team members (Students } 1 \\
\text { and 2) continuing. }\end{array}$ \\
\hline Venture Delta & Student 3 & Incorporated in December 2013 & One original team member (Student 3) continuing. \\
\hline Venture Omega & & Development phase & $\begin{array}{l}\text { Last original team member leaving in January } 2014 \text {, } \\
\text { mainly due to lack of financing (the limited budget was } \\
\text { allocated to technical verification activities). }\end{array}$ \\
\hline Venture Epsilon & Student 4 & Development phase & $\begin{array}{l}\text { One original team member (Student } 4 \text { ) continuing with } \\
\text { plans for incorporation, but very dependent on } \\
\text { financing. }\end{array}$ \\
\hline
\end{tabular}

(Gamma, Delta, Epsilon and Zeta - shown in Table 1 in bold type) are included.

\section{Data analysis}

In order to analyse data collected regarding the nascent entrepreneurs, we established an initial thematic scheme (Polkinghorne, 1995), building upon traditions of narrative (Czarniawska, 2004; Downing, 2005), for selection of excerpts from written documentation and quotations from transcribed interviews in particular. The template consisted of four main themes:

(1) Who I am - the student's perspective of their own skills and capabilities;

(2) What the venture is - the student's perspective on what the venture is and what it needs;

(3) How I fit in - the student's perspective on their role in the venture; and

(4) Development of the student's understanding of the 'role' of entrepreneur.

The first theme addresses the description of the nascent entrepreneur as an individual, providing data about aspects which may contribute to existing identities, and relating to the ' $\mathrm{I}$ ' in the dialogics. The second theme is intended to capture description of the venture being created, and therefore relates to the ' $\mathrm{NVC}$ ' in the dialogics. Primarily these descriptions stem from the perspective of the nascent. However, given the environment, the nascent entrepreneurs are in interaction with, and can be regarded as being influenced by, descriptions provided by other key actors such as incubation staff members, the providers of the ideas, faculty and other advisors. The third and fourth themes are intended to address the expectations of the entrepreneurial role, and thus relate to the 'ERE' in the dialogics.

Each author independently reviewed the transcribed interviews, identifying quotations exemplifying the four themes as they related to 'individual' (who I am), 'new value creation' (what the venture needs), and 'entrepreneurial role expectation' (who I want to be/become). Written documentation from the individuals/teams was also individually reviewed to identify additional descriptions of 'individual', 'new value creation', and 'entrepreneurial role expectation'. The independently determined interview quotations or selections from written documents (team formation document and business plans) were comparatively analysed before selection for use, in order to reduce individual bias or interpretation of data.

The written documentation - the team formation documentation and business plan - were analysed to select text in which the nascent entrepreneurs presented descriptions associated with the themes. For example, in the team formation document, text in which a student describes his or her background, skill-set and other contributions regarded as valuable for the venture, is selected. This document also provided evidence regarding personal preference of which idea to work with during the incubation period (stated as ranking $1 \mathrm{st}, 2 \mathrm{nd}$, etc, in Table 3), considered as addressing the new value creation theme. ${ }^{5}$ In the business plans, text selected included role descriptions presented in the organizational section, and statements describing the venture. 
Together, the interviews and documentation provide a timeline from May 2012 to May 2013. The interviews and team formation documents provide individually constructed statements, whereas the business plans provide statements produced collectively. The iteration of individually and collectively produced text allows for a degree of triangulation of data collected (Flick, 2006), providing convergence with regard to identified themes, and increasing the viability of the text used to support our argumentation (Creswell and Miller, 2000).

\section{Results}

Evidence accounted for in the Findings section was extracted from a larger dataset found in Tables 2, 3 and 4. To recall: Table 2 presents the theme 'individual'; Table 3 presents the theme 'new value creation' with the venture determined as representative of the value being created; and Table 4 presents the theme 'role'. Each table presents data for each individual from four data points, organized temporally from left to right in columns: Team formation May 2012, Business Plan October 2013, Interview February 2013 and Business Plan June 2013. Because role descriptions were particularly dependent upon data from the February 2013 interviews, short summaries of the quotations are provided in Table 4.

\section{Findings}

In the following section, we address empirical evidence identified as relevant for the following categories:

- Examples of I $\leftrightarrow \mathrm{NVC}$ dialogic and how it changes over time;

- Examples of I $\leftrightarrow$ ERE dialogic and how it changes over time; and

- Examples of ERE $\leftrightarrow \mathrm{NVC}$ dialogic and how it both changes over time and pertains to the immediate team environment.

\section{$I \leftrightarrow N V C$ dialogic}

Student 3 of Venture Delta related to NVC during team formation. The student has an educational background (BSc) in industrial engineering.

'I am convinced that [Venture Delta] has great potential. I am excited about the field of application which aligns with my passion for healthcare.

[Venture Delta] has a functioning technique and a confirmed market need - it could reach the market within a short period, an aspect I prioritize as I would probably not stay in a project with a $10+$ year to market. Being part of a project that I can follow all the way to product launch would be awesome. I hope for continuation after the incubation period.' (Student 3 , team formation)

Student 4, with a business administration background related to NVC in the following way during team formation:

'I have a major interest in environmentally sustainable energy. [Venture Epsilon] has an exciting development potential in renewable energy. I will do my upmost to be a part of bringing [Venture Epsilon] to commercial scale along with a team and collaborative partners. I have a personal interest in continuing with [Venture Epsilon] if the opportunity presents. I realize this will require hard work and persistence - I expect a great challenge, but that is why I am here and choose [Venture Epsilon].' (Student 4, team formation)

One of the students in Venture Zeta discussed individual association to NVC both during team formation and six months later. The student has an educational background in industrial engineering.

'Too technical and too long time to market for my taste. I don't understand the technology.' (Student 6, having ranked this venture as her last choice in team formation)

'I can never see confirmation of that what I spent the last two weeks on that was actually bringing value to the [Venture Zeta] because nobody has the rights or the wrongs so myself I have to decide that this was good for [Venture Zeta] [. . . ] there's no right answers and there's no reference at all, so you don't know if you're on the right track [. . . I I spent 12 hours working on this, 13, 14 hours working on this presentation and nobody's going to tell me if it's good or not. I can practise, practise, practise, practise, and I can still stumble and say something wrong on the presentation. Did I fail, did I not, did I do a good job, I don't know.' (Student 6, Quotation 8 from February interview)

Table 2 shows that all the nascent entrepreneurs (Students 1-6) stated a change in the personal description provided in the October business plan (third column) compared to the May business plan (fifth column). In the latter descriptions, the nascents positioned themselves more specifically in terms of the needs of the venture, and in some cases also identified specific functional roles, as discussed in the next section. 
Table 2. Individual - who I am.

$\begin{array}{lll}\begin{array}{l}\text { Student } \\ \text { ID }\end{array} & \text { Team formation May 2012 } & \begin{array}{l}\text { Business plan October } \\ \mathbf{2 0 1 2}\end{array} \\ 1 & \begin{array}{l}\text { Biotechnology, good at } \\ \text { calculations and modelling. }\end{array} & \begin{array}{l}\text { BSc Biotechnology; expertise } \\ \text { from process industries; } \\ \text { technology interest; social; } \\ \text { open minded. }\end{array}\end{array}$

$2 \quad$ Analytical mindset. Perform well in complex situations; use network of friends to solve problems faster. Possess good social skills; able to jump quickly into different scenarios and perform well. Often take a leadership role, getting each individual to perform at their best. Goal-driven, structured, effective multi-tasker.

3 Visionary; enthusiastic about ideas I want to realize. Lose motivation if not moving forward. Like to look at things from an overall perspective. Not into the nitty-gritty details.

Very strong analytical person. Ability to structure, organize and lead. Can-do attitude; strong drive to pursue goals; optimistic (sometimes over-optimistic); detail-oriented; committed. Knowledgeable in technology and science within biotech and chemistry.

Dedicated, contributing with a positive attitude under pressure. Organized; push productivity. Experience from military career. Background in mechanical engineering. I do not mind digging into fields where I have no knowledge. Enjoy contacting different kinds of people. Work is often structured and focused towards a deadline.
BSc Industrial engineering and management; management consulting experience; experience of marketing and sales; curious; analytical.

BSc Industrial Engineering and Management.

BSc Industrial Engineering and Management, minor in Chemical Engineering. Experience in organizational development, strategy and finance. International work experience from Norway, Japan and Singapore. nergetic, take initiative;

\section{Interview \\ Feb 2013}

MSc Entrepreneurship and Business Design (June 2013); BSc

Biotechnology. Experienced in business idea evaluations and large-scale processing, which supports product development activities and large party relations in the venture.

MSc Entrepreneurship and Business Design (June 2013); BSc Industrial Engineering and Management. Work experience includes management consultancy as well as experience from marketing and sales which allows for efficient approach towards sales and customer relationship in the venture.

\section{Quotation 18}

Part of the business development team. MSc Entrepreneurship and Business Design (June 2013). BSc Industrial Engineering and Management. The team is highly motivated to make this innovation reach the market.

BSc Industrial Engineering and Management; MSc Entrepreneurship and Business Design (June 2013). International work experience in business development in IT firms and in the maritime sector (Japan, Singapore and South East Asia).

Quotation 4

Quotation 8, Quotation 14
BSc Mechanical Engineer; MSc Entrepreneurship and Business Design (June 2013). Winner of the world's largest competition for engineering students 2013 . positive and accommodating. Like things stated in black and white; like to focus on quantifying abstract ideas. Work experience in economics, accounting and financing (Sweden and USA). 


\section{$I \leftrightarrow$ ERE dialogic}

Student 1 of Venture Gamma made multiple references to ERE, both in team formation and in the February interview. In the May version of the business plan, Student 1 is listed as responsible for product development and large party relations (Table 4 , fifth column).

'I want to learn and work hard to make the project successful and possible to continue with as a venture (post incubation period).' (Student 1 from team formation)

'I think what I was missing during the autumn was more structured roles and, leadership is a part of the role, maybe I didn't think of that in particular because I think that we're very driven all of us and we have pretty similar goals and ambitions so it's not like, at least I don't feel that I need a leader to set goals and I didn't really feel that I was missing someone leading the way, but I missed some kind of structure so we could work more efficiently, so I don't have to keep track of everything, I can just focus on my three different parts, but not everything, so lack of structure where leadership is one part of it.' (Student 1, Quotation 39 from February interview); and continuing along the same line. . .

'I think it would probably be good to make sure that everyone has an equal say, but it would probably be so that the person who is CEO has a bit more responsibility and also the ability, someone has to make quick decisions sometimes, and I think the result would be that someone does have a bit of additional power, and that's not strange.' (Student 1 Quotation 41 from February interview)

Student 4 discussed a role taken, not particular to the venture, but rather for the good of the venture through how other members of the team contribute.

'I cannot pinpoint on what I'm really good at. I kind of notice that I might be the one [. . .] the strengths might be that I'm trying to coordinate [my team-mates] to the very best, in some sense and trying to pull out the strengths of the others.' (Student 4, Quotation 18 from February interview)

Both students (5 and 6) of Venture Zeta related to ERE in the midst of the first venture year. Student 5, with a mechanical engineering background, was made responsible for product development (as stated in the business plan written a year after team formation, Table 4). Student 6 , with a background in industrial engineering, was responsible for finance and IP (as stated in the business plan, Table 4). Both students stand out in the sample by having initially downgraded the venture, as shown by their low ranking of the venture idea (as either last or second to last preferred choice during team formation, Table 3 second column), whereas the students from the other ventures communicated high values for their venture ideas (listed as either first or second preferred choice during team formation, Table 3 second column). Nonetheless, by the February interviews, both Student 5 and 6 were stating their commitment to the venture:

'I and [Student 6] have chosen to continue with the project and [our other team-mate] is not convinced. I don't know how official that is, but, between you and me, and of course that changes a little bit the group dynamics, that it affects like ambition, motivation, commitment, it's not that [our other team-mate] is not committed, but I can see a little bit of a change.' (Student 5, Quotation 3 from February interview)

Even so, Student 6 communicated self-doubt, using venture team-mates as comparison points. An additional quotation also illustrates how positioning and comparison within the team contributes to role adoption within the venture:

'Both [Student 5] and [our other team member] are very strong team members, not strong in their will but very solid and works hard and works a lot and gets things done. So there are a lot of situations where you feel sometimes, "Did I do enough?', I mean did I pull my weight now? You don't want to disappoint them, and you don't want to [let them down], but yeah, so sometimes I feel like ... What am I actually bringing to the table?' (Student 6 , Quotation 7 from February interview)

'I think I am a little bit more, I want to get stuff done so I want to take like decisions and see that we're making progress and, whereas [our other team-mate] is a little more, 'wait, wait, let's see all the alternatives' and analyse everything [. . .] I'm always pushing for let's move forward and [the other team-mate] would always push for let's take it easy, so I think that's a good complementary. [ . . .] Part of me is getting better at this skill, that I'm better at taking all these abstract things and making them more concrete.' (Student 6, Quotation 13 from February interview)

\section{ERE $\leftrightarrow$ NVC dialogic}

Dialogic between NVC and ERE is identified for five of the six nascents in the February interviews (Table 3). 
Table 3. New value creation - what the venture needs.

\begin{tabular}{|c|c|c|}
\hline $\begin{array}{l}\text { Student } \\
\text { ID }\end{array}$ & Team formation May 2012 & $\begin{array}{l}\text { Business plan October } \\
2012\end{array}$ \\
\hline 1 & $\begin{array}{l}\text { Ranked high ( } 2 \text { nd choice). I } \\
\text { believe that [an idea] like this } \\
\text { will be a part of the future } \\
\text { medical system. I see many } \\
\text { benefits [as it will] be a very } \\
\text { good tool. Most focus would } \\
\text { be to connect all pieces, } \\
\text { communicating the value and } \\
\text { creating a user-friendly } \\
\text { interface. A competitive field. }\end{array}$ & $\begin{array}{l}\text { Venture Gamma will provide } \\
\text { patients with an empowering } \\
\text { product and service to } \\
\text { increase medical knowledge, } \\
\text { compliance and improve } \\
\text { health outcomes. The vision } \\
\text { is to lead the transformation } \\
\text { of the health care system by } \\
\text { putting the patient in the } \\
\text { centre and deliver the best } \\
\text { personalized care. }\end{array}$ \\
\hline
\end{tabular}

Ranked high (1st choice). An extremely interesting case with great potential. I would like to work with [Venture Gamma] due to the fact that one is able to work in a start-up format closely tied to a big firm. Furthermore I believe that my experience from working with big firms and challenging cases would come in useful when understanding the approach to the idea.

\section{Interview}

Feb 2013

Venture Gamma will provide patients with an empowering product and service to increase medical knowledge, compliance and improve health outcomes. The vision is to lead the transformation of the health care system by putting the patient in the centre and deliver the best personalized care.
Venture Delta aims to
increase the awareness of the harm caused by this ventilation process by developing a monitoring device and provide healthcare personnel with direct feedback and data for documentation and analysis.
Venture Delta will provide the market with a web-based platform to access the data and give researchers the opportunity for data analysis and knowledge sharing.

\section{Business plan May 2013}

Venture Gamma will be developing the product together with a key partner to improve the solution as technology changes within the adherence area are happening at an increasing rate. The electronic GSM module will be developed. Multiple POC studies will be conducted to establish product benefits and gain adoption. Focus on creating strong and good relations with pharmaceutical producers in order to realize the business plan.

Quotation 34 Quotation 36

Venture Gamma will be developing the product together with a key partner to improve the solution as technology changes within the adherence area are happening at an increasing rate. The electronic GSM module will be developed. Multiple POC studies will be conducted to establish product benefits and gain adoption. Focus on creating strong and good relations with pharmaceutical producers to realize the business plan.

\section{Quotation 22}

\begin{abstract}
Venture Delta needs to find strategic alliances for production and distribution and to use international medical networks, key opinion leaders and clinical training centers for market penetration. Critical actions prior to making any alliances: continued product development, clinical trials for regulatory approval, prototype feedback and market verification.
\end{abstract}

These interactions captured how individuals interrelated NVC and ERE as affected by the immediate (team) environment.

'I haven't applied for any jobs yet. It's either continuing with this project or doing something quite similar. Finding some kind of innovation project that has maybe gone a bit further.' (Student 3, Quotation 22 from February interview)
'... what I' $m$ doing now here is valuable, I see the value in doing it, and then some activities are um, ok, we're doing this but I cannot stand for what I'm doing is the opinion of some of us and that becomes like 'ok, you don't have um, you find it boring and you don't see any value in doing it, but someone has to take the responsibility of doing it' and that's kind of the root cause of everything.' 
Table 3. Continued

\begin{tabular}{|c|c|c|c|c|}
\hline $\begin{array}{l}\text { Student } \\
\text { ID }\end{array}$ & Team formation May 2012 & $\begin{array}{l}\text { Business plan October } \\
2012\end{array}$ & $\begin{array}{l}\text { Interview } \\
\text { Feb } 2013\end{array}$ & Business plan May 2013 \\
\hline 4 & $\begin{array}{l}\text { Ranked high (1st choice). I } \\
\text { have a major interest in } \\
\text { environmentally sustainable } \\
\text { energy. [Venture Epsilon] has } \\
\text { an exciting development }\end{array}$ & & Quotation 20 & $\begin{array}{l}\text { A complete installation of several } \\
\text { [Venture Epsilon] units will require a } \\
\text { significantly large degree of } \\
\text { infrastructure development, including } \\
\text { site installation and energy transfer. }\end{array}$ \\
\hline
\end{tabular}

Quotation 4; $\quad$ Prototype testing has been initiated Quotation 5; Quotation 11

Quotation 10 together with financiers and industry market verification, and prototype market in 2015. partners. [Venture Zeta's] key activities are product and customer development, testing. Goal is have a product on the

\footnotetext{
Prototype testing has been initiated together with financiers and industry partners. [Venture Zeta's] key activities are product and customer development, market verification, and prototype testing. Goal is have a product on the market in 2015.
}

(Student 4, Quotation 20 from February interview)

'I'm the representative of [Venture Zeta], and this is a very important task and everybody needs to focus, if you don't have that role, or somebody taking that role, you need to talk more.' (Quotation 4); and

'Usually the task we do, no one knows how to do them, so I think there is a higher chance of failing, usually, which makes it sometimes like, ok I'm responsible for this, like translating the patent, $\mathrm{OK}$ I'm responsible for this, and if I fail, the consequence is huge.' (Quotation 5) (Student 5 from February interview)

'Right now, we haven't been into a critical moment or situation where everything depends on making fast decisions and taking a lot of responsibility. I definitely see in the future that we could have responsibility areas and it's starting to divide a little bit, but, yeah, I do think that we could benefit from that.' (Student 6, Quotation 10 from February interview)

The following, final quotation represents not only an ERE $\leftrightarrow$ NVC dialogic but also connects with I $\leftrightarrow$ ERE dialogics:

'We all felt during all of autumn that it would be good to have more roles, but at the same time we didn't know which roles we should take or who should take what role and technically if it would be better, [one team-mate] has more IT knowledge, [Student 1] has more biotech, and I have a bit more sort of the management or that kind of role, so 
Table 4. Role - what I want to become.

\section{Student Team formation May ID 2012 \\ $1 \quad$ Want to learn and work hard to make the project successful and possible to continue with as a venture (post-incubation period).}

\section{Business plan October \\ 2012}

Interview Feb 2013

Quotation 39: role distribution allows me to focus on what I want/need to do.

Quotation 41: would like to become a leader, but not there yet.

Quotation 34: the challenge of role distribution. Quotation 35: feeling that setting the roles limits becoming entrepreneurial. Quotation 37: there needs to be a CEO.

Quotation 22: this is what I want to do. Quotation 24: positioning within the team, based on perceived personal strengths. Quotation 25: the need for role distribution because everyone is still involved in everything. Quotation 28: the team is positioned (guided) by an external actor.

Quotation 18: trying to fit self into a role. Quotation 19: positioning relative to one another based on skills, interests, values, etc towards what was useful for the project.

Quotation 3: 'me and [student 6] choose to continue'. Quotation 9: not having clear 'titles' but areas of responsibility. military approach to ensure that team-mates do not feel stressed by deliverables or deadlines. I have been told I often have valuable input and should speak my mind more often. I aim to be honest towards people and give feedback on their actions for various reasons. should we go straight for taking those kind of roles, which be the easy path [...] what's best for the project isn't always what's best for the learning consists of three individuals which hold the operational responsibility to drive the project forward on a daily basis. All three individuals are current students at Chalmers School of Entrepreneurship and they have previously worked together successfully.

Business plan May 2013

Product development and large party relations.

Sales and customer relations.

Sales and finance.

Communication, financing and fundraising.

Product development.

Quotation 10: see need for role distribution. Quotation 13: I am the doer, action-oriented one driving the venture forward. Quotation 15: an alumni helps set direction and team sees value in it.
Finance and IP. experience. And I think we're still struggling to get separated enough roles.' (Student 2, Quotation 34 from February interview) 


\section{Discussion}

Previous research into entrepreneurial identity has primarily had an instrumental view - 'you are what you do', often also assuming 'you do what you intend'. Many understandings of nascent entrepreneurship rest upon interpretations of the theory of planned behaviour (Ajzen, 1991); that is, that entrepreneurial intent can predict entrepreneurial behaviour (i.e., becoming entrepreneurial) which in turn (instrumentally) results in entrepreneurial identity. In this article we have sought to develop and explore empirically an understanding of entrepreneurial identity stemming from dialogics between the individual (I), new value creation (NVC) and entrepreneurial role expectations (ERE), a view which is interactive and relational, while not taking for granted that intention or functional behaviour are sufficient factors for entrepreneurial identity to emerge.

This study positions entrepreneurial identity instead as socially embedded and constructed (Aldrich and Zimmer, 1986; Donnellon et al, 2014), emphasizing the use of a perceived role when in a nascent phase. First, the discussion will analyze empirically findings accounted for in the previous section in relation to the proposed model (Figure 2) which builds on the work of Bruyat and Julien (2001). Second, we elaborate on how the empirical findings, in relation to Figure 2, stimulate further theorizing with regard to nascent entrepreneurial identity. Finally, we discuss how the study provides arguments to question the use of theory of planned behaviour (Ajzen, 1991) as well as other more functional perspectives concerning nascent entrepreneurship.

\section{Analysing empirical findings in relation to the conceptual model}

In the Findings section, we accounted for evidence identifying I $\leftrightarrow \mathrm{NVC}$ as well as I $\leftrightarrow$ ERE dialogic from some but not all of the nascent entrepreneurs. The $\mathrm{I} \leftrightarrow \mathrm{NVC}$ dialogic is most explicit in the early venture formation stage, where the nascent surrogate entrepreneurs are required to express preferences with regard to all the venture ideas offered to them. Some, but not all, then relate themselves to NVC.

Student 4 is a clear example of an I↔NVC dialogic, associating with the sustainability quality of Venture Epsilon in the team formation statement. Interestingly, in the same statement, Student 4 also states,

'I realize this will require hard work and persistence - I expect a great challenge, but that is why I am here and choose [Venture Epsilon]', which shows a connection to a societal metaphor of the entrepreneur as facing challenges and requiring hard work and persistence to achieve venture success. In this way, Student 4 seems already to display connection to an entrepreneurial identity, albeit understood more through societal norms and associated with the general process of value creation. What is also interesting is that while Student 4's societal metaphor supports the connection to new value creation in the form of Venture Epsilon, this is not the case for a team-mate. In an interview quotation from an individual not selected for the empirical presentation, there is also a statement associated with a general perspective of new value creation. Student 4's team-mate (who did not continue with Venture Epsilon) explains a lack of identity with the venture based on existing competency base:

'There weren't really any projects that I felt I could use my knowledge and background in [. . .] in retrospect I think it was doomed from the start because of my perspective on this way of doing start-ups [. . .] I want to combine entrepreneurship with things I know, but I don't know anything about [the technology underlying Venture Epsilon].' (Team-mate of Student 4, Quotation 21 from February interview).

While our findings support the I $\leftrightarrow$ NVC dialogic, they also focus specific attention on the effect of being in a nascent phase, illustrating that this nascent state may require more explicit association with a localized 'entrepreneurial role' in order to establish 'provisional selves' (Ibarra, 1999) as part of the entrepreneurial identity formation. For many of the nascents, the I $\leftrightarrow$ NVC dialogic appears to weaken in the February interviews. At this point, many of the nascents struggle to determine their position relative to value being created, in part because the value creation has become more specifically defined in terms of the venture needs. Their initial claim regarding an entrepreneurial identity during the team formation, based on a societal (generic) entrepreneurial role expectations, has dissipated because of the demands of the venture; and, at the same time, their other existing identities (for example 'engineering student') are not sufficient. This is observed, for example, in Student 6's self-doubt in Quotations 7 and 8 , or Student 4's 'I cannot pinpoint what I'm really good at' in Quotation 18. The February interviews illustrate that the nascents were moving away from the more generic role expectations of the entrepreneur articulated in their team formation documents (Table 2, second column) towards more specific role expectations driven by their immediate (team) environment. This supports the literature that identifies the limitation of 
projected entrepreneurial myths in contributing to individuals become entrepreneurial (Drakopoulou Dodd and Anderson, 2007; Ogbor, 2000).

Nonetheless, having a weak initial association with the venture idea (as Student 4's team-mate mentioned earlier), or doubts during the process, does not prevent $\mathrm{I} \leftrightarrow$ NVC development over time. Students 5 and 6 both initially ranked the idea behind Venture Zeta very low, in terms of preference and perceived value (Table 3, second column). Student 6's statement in team formation - 'Too technical and too long time to market for my taste. I don't understand the technology' mirrors that of Student 4's team-mate. Student 6 still illustrates some doubts about capabilities with regard to what the venture needs, but nonetheless is shown to be committed to the future of the venture (Student 5's Quotation 3), and Student 5 clearly states a position in connection with new value being created by claiming a direct role in the venture - 'I am the representative of Venture Zeta' - in Quotation 4. Given the strong commitment that both nascents (Students 5 and 6) continued to display around the venture to the time of writing (end of January 2014), and the extensive legitimacy they have obtained in running the venture, there appears to be a profound transformation for both nascents, from alienation towards NVC, to being key venture representatives.

With regard to the I $\leftrightarrow$ ERE dialogic, there are several quotations offered from the February interviews. A common denominator in these is how much the individual, when relating to ERE, does so while also relating to other team members; as seen, for example, with Student 2 (Quotation 34), Student 4 (Quotation 18) and Student 6 (Quotations 7 and 13). The quotations display ambivalence between taking on specific functional roles and remaining responsible for the holistic venture development. Although all respondents communicated a more specialized role in the business plan (May version), in the February interviews they also displayed ERE that was holistic rather than specialized. This parts-to-whole tension seems worthy of further study.

These examples also illustrate ways in which ERE can play a mediating role within the I $\leftrightarrow$ NVC dialogic in developing an entrepreneurial identity. Student 6 showed commitment to the NVC despite expressing doubts over their own ability to develop a venture with the specific technology. Over time, understanding of the entrepreneurial 'role' transformed such that Student 6 committed to and could identify with both the venture and the role of the entrepreneur developing that venture despite initial alienation.

A handful of quotations are identified as illustrating dialogic between NVC and ERE and all are from the February interviews (that is, later in the process). In some circumstances clear implications can be drawn from the students' more profound perceptions regarding which kind of NVC as well as ERE is attractive. Hence the NVC $\leftrightarrow$ ERE dialogic seems, at least indirectly, to help the students to develop a more anchored individual entrepreneurial identity, in that this dialogic is concerned with whether or not there is an attractive enough entrepreneurial role that is identified, for the individual to choose as a future career. For example, Student 5 , having communicated commitment to Venture Zeta in Quotation 4, stated the responsibility to that role of the venture representative, separate from an individual association to value creation (patent analysis). Student 3 (Quotation 22) indicated that, if unable to go forward with Venture Delta, then there was a preference for taking on any entrepreneurial position similar to the experience just gone through, rather than looking for another career - for example, associated with the previous identity. In other words, some nascents were building their entrepreneurial identity as much, or even more, from seeing a fit between a role expectancy and the new value to be created (ERE $\leftrightarrow \mathrm{NVC}$ ) than only relating themselves to the new value (I $\leftrightarrow \mathrm{NVC}$ ) or to a more generic entrepreneurial role (I $\leftrightarrow \mathrm{ERE})$.

So far we have analysed how the empirical findings help illustrate the use of the proposed conceptual model consisting of three dialogics, all potentially having an effect on entrepreneurial identity (Figure 2). In comparison with the original I $\leftrightarrow$ NVC dialogic offered by Bruyat and Julien (2001) (Figure 1) the main added features are entrepreneurial role expectations (EREs), affected in particular by an immediate team environment (Figure 2). ERE is introduced as an intermediary concept relevant for individuals not yet confident as entrepreneurs - that is, not yet having obtained the entrepreneurial identity, this latter being a central notion in the entrepreneurial learning literature or, for example, associated with expert entrepreneurs (Sarasvathy, 2008). The introduction of ERE also implies empirical interest into three dialogics rather than just one. Although not all the students in the study expressed themselves in relation to all three dialogics, it was still possible to illustrate all dialogics through the empirical findings, contributing to the literature dealing with entrepreneurial identity construction in a nascent phase (Nielsen and Lassen, 2012; Rigg and O'Dwyer, 2012; Williams Middleton, 2013). This offers relevancy to the proposed framework, although explanatory value certainly can be improved through further study.

\section{Further theorizing on entrepreneurial identity}

Our article offers some empirical indications worthy of further discussion. First, the dialogics appear somewhat 
sequentially. The I $\leftrightarrow$ NVC dialogic appears before the other two dialogics; over time, the other two dialogics become more prominent, while the I $\leftrightarrow$ NVC dialogic becomes less identifiable. On the basis of the evidence of this study it could thus be suggested that development of entrepreneurial identity requires experiential engagement with concrete new value creation, which is then also in strong alignment with the work of Bruyat and Julien (2001).

However, the relevance of the I $\leftrightarrow$ ERE and ERE $\leftrightarrow$ NVC dialogics becomes apparent with time. These two dialogics could be regarded as crucial for individuals who ultimately pursue more entrepreneurial careers, whether that arises from experiencing a sufficiently attractive role expectation regarding the specific new value creation (i.e., stemming primarily from $\mathrm{ERE} \leftrightarrow \mathrm{NVC}$ dialogics) or from the individual having gained confidence in an entrepreneurial role which potentially could be related to some other venture situation (identity stemming primarily from I $\leftrightarrow$ ERE dialogics). Notably, the immediate team environment has strong effect on both of these dialogics, once again confirming the strong embedded and social nature of entrepreneurial learning (Hytti and Nieminen, 2013; Rae and Wang, 2015; Williams Middleton and Donnellon, 2014).

\section{Relating to the theory of planned behaviour}

Applications of the theory of planned behaviour to entrepreneurial development tend to emphasize a linear development towards becoming entrepreneurial. This is in contrast to the transformational development of entrepreneurial identity through dialogics as shown above, where becoming entrepreneurial is strongly affected by both role expectations and new value creation. If we applied our dialogic model to the general understanding of the theory of planned behaviour the initial dialogic would be between the individual and the role expectation (representative of entrepreneurial beliefs and attitudes), which would then lead to an entrepreneurial intention regarding new value creation, similar to an I $\leftrightarrow$ NVC dialogic. What we see instead is that relating to new value creation is a critical first step, and that entrepreneurial role expectations are not primarily something societal and pre-existing but, rather, something affected by the immediate team environment and developed in a dialogic with both new value creation as well as the individual identity. We argue that further study is needed to investigate this critique of how the theory of planned behaviour is applied. Aspects other than that of intentions, such as dialogics with role expectations and with the value created, are regarded as having a greater impact on how entrepreneurial identity emerges. We argue that an instrumental view of entrepreneurial identity ('you are what you do') is insufficient, and that research addressing entrepreneurial emergence would benefit from applying an understanding based on dialogics between individual identity, new value creation and entrepreneurial role expectations.

\section{Conclusions}

This article explores how nascent entrepreneurial identity is constructed and reconstructed through a process involving dialogics between individual, new value creation dialogics and entrepreneurial role expectations. Much research into becoming entrepreneurial applies an instrumental - you are what you do - perspective. Such research often also relies upon a simplistic interpretation of the theory of planned behaviour ('you act as you intend'). This article identifies how individuals, having become entrepreneurial, applied an I↔ NVC dialogic in the earliest phase of their entrepreneurial emergence and, over time, also applied I $\leftrightarrow$ ERE and ERE $\leftrightarrow$ NVC dialogics. The evidence suggests that entrepreneurial identity development as associated with the initial $\mathrm{I} \leftrightarrow \mathrm{NVC}$ is reified through attribution to an entrepreneurial role in the early stages of entrepreneurial emergence. As the nascent phase progresses towards incorporation, and then in particular a dialogic between the immediate (team) environment and the new value, the entrepreneurial identity development emphasizes $\mathrm{I} \leftrightarrow \mathrm{ERE}$ as well as ERE $\leftrightarrow \mathrm{NVC}$ dialogics.

This article, using the concept of entrepreneurial role expectations, adds an entrepreneurial learning perspective to the I $\leftrightarrow \mathrm{NVC}$ dialogic originally proposed by Bruyat and Julien (2001) as defining the phenomenon of entrepreneurship. We have illustrated empirically, here, how entrepreneurial identity is to a large extent developed as a result of individuals both interacting with new value creation and being affected with regard to their entrepreneurial role expectations by their immediate team environment. This understanding is far from an instrumental - 'you are what you do' view of nascent entrepreneurship. It stands in contrast to the prevalent view of intention preceding and implying behaviour, as used in designs for becoming entrepreneurial.

The conclusions from the article are indicative and need to be substantiated with more empirical evidence. Although the empirical investigation was carried out in a designed venture creation programme, it could still be argued that the proposed conceptual model may have general merit and thus would be applicable in other learning spaces and training environments. Important modifying factors could include identifying whether or 
not nascent entrepreneurs have a history of family entrepreneurial activity. The impact of the team environment, manifestly apparent in the empirical data, might not appear as clearly or illustratively in processes where a venture is initiated by a single founder who then may require much more time to assemble and build a venture team.

A final potential implication from the present study is that NVC introduced to the entrepreneurial education literature does add new ideas about learning and identity construction which possibly are difficult to obtain otherwise. Further studies need to substantiate this tentative conclusion. Furthermore, if ERE dialogics are crucial for becoming entrepreneurial, then further studies also need to investigate the ways in which these dialogics can make such a difference. Given the dramatic transformation of some of the examples in the study from initial alienation to becoming lead entrepreneurs of a recognized promising technology venture (for example, the venture concerned was an award winner in business competitions), there are apparently strong forces at play. Questions remain, however, about how these forces occur and what is required to enable them, drawing attention to additional educational (and learning) design and assessment studies.

\section{Limitations}

Insider action research is susceptible to criticism with regard to researcher proximity to the data used, which can potentially limit objectivity. However, such a critique is based on research models in which the investigation is dependent upon complete control over variables affecting experimental outcomes, which is not the case when a contextual basis is part of the research design (Shani et al, 2008). When the research model is completely controlled, there is the possibility of designing with a view to the intended outcome. Research with a contextual basis means that the researcher(s) do not control influencing variables; rather, the insider status allows for contextual understanding and observation.

Another potential limitation of the study is the sample size. The small data population (four teams, six individuals) limits the ability to draw generalizations from the study. However, because the research is explorative and qualitative in nature, its value lies in the in-depth knowledge that studying a smaller sample provides and thus can be regarded as viable given the nature of the study. Potential bias arising from interpretation of interview data is reduced by means of initial independent analysis conducted, then discussed collectively, by the three authors in order to test the concordance of the results.

\section{Notes}

${ }^{1}$ Lundqvist and Williams Middleton are the equal first authors, and Nowell is the second author.

${ }^{2}$ Describing behaviour or belief in terms meaningful (consciously or unconsciously) to the actor; culturally embedded. This is emphasizing the social construction of the entrepreneurial role concept, emphasizing the localization of the social construction. ${ }^{3}$ This does not pertain to, as mentioned in the introduction, family firms or franchise operations. Separate literature has addressed entrepreneurial identity construction within family firms - see for example Hamilton (2011).

${ }^{4}$ Team formation is conducted prior to the nine-month incubation period, at the end of the first year of the two-year programme.

There is a three month gap between the first and second year (the nine-month incubation period) during which the students have a summer hiatus. Team formation is completed prior to this gap so that members have the opportunity to interact as a team and initiate investigation into the venture idea during the summer hiatus.

${ }^{5}$ Student teams work with only one idea at a time, and the design of the programme is such that one idea is developed into a venture during final year of the education. However, if, through development, the team determines that the idea does not have commercial potential, they can shut it down, and initiate development of a new idea. None of the ventures in the empirical study of this article were shut down during the programme period and thus the students interviewed as part of the study were working on their associated venture only (i.e., not working with multiple ventures).

\section{References}

Ajzen, I. (1991), 'The theory of planned behavior', Organizational Behavior and Human Decision Processes, Vol 50, No 2, pp 179-211.

Aldrich, H.E., and Zimmer, C. (1986), 'Entrepreneurship through social networks', in Sexton, D., and Smilor, R., eds, The Art and Science of Entrepreneurship, Ballinger, Cambridge, MA.

Anderson, A.R. (2005), 'Enacted metaphor: the theatricality of the entrepreneurial process', International Small Business Journal, Vol 23, No 6, pp 587-603.

Anderson, A.R., and Warren, L. (2011), 'The entrepreneur as hero and jester: enacting the entrepreneurial discourse', International Small Business Journal, Vol 29, No 6, pp 589-609.

Blenker, P., Korsgaard, S., Neergaard, H., and Thrane, C. (2011), 'The questions we care about: paradigms and progression in entrepreneurship education', Industry and Higher Education, Vol 25, No 6, pp 1-11.

Boulding, K.E. (1956), 'General systems theory: the skeleton of science', Management Science, Vol 2, No 3, pp 197-208.

Brannick, T., and Coghlan, D. (2007), 'In defense of being "native": the case for insider academic research', Organizational Research Methods, Vol 10, No 1, pp 59-74.

Bruyat, C., and Julien, P.-A. (2001), 'Defining the field of research in entrepreneurship', Journal of Business Venturing, Vol 16, No 2, pp 165-180.

Carsrud, A.L., and Johnson, W.R. (1989), 'Entrepreneurship: a social psychological perspective', Entrepreneurship and Regional Development, Vol 1, No 1, pp 21-31.

Cast, A.D. (2004), 'Well-being and the transition to parenthood: an identity theory approach', Sociological Perspectives, Vol 47, No 1, pp 55-78.

Clarke, J., and Holt, R. (2010), 'The mature entrepreneur: a narrative approach to entrepreneurial goals', Journal of Management Inquiry, Vol 19, No 1, pp 69-83.

Coghlan, D. (2001), 'Insider action research projects: implications for practising managers', Management Learning, Vol 32, No 1, pp 49-60. 
Coghlan, D. (2007), 'Insider action research: opportunities and challenges', Management Research News, Vol 30, No 5, pp 335-343.

Coghlan, D., and Brannick, T. (2005), Doing Action Research In Your Own Organization, Sage, London.

Cope, J., and Watts, G. (2000), 'Learning by doing: an exploration of experience, critical incidents and reflection in entrepreneurial learning', International Journal of Entrepreneurial Behaviour and Research, Vol 6, No 3, pp 104-124.

Corbett, A.C. (2005), 'Experiential learning within the process of opportunity identification and exploitation', Entrepreneurship Theory and Practice, Vol 29, No 4, pp 473-491.

Creswell, J.W. and Miller, D.L. (2000), 'Determining validity in qualitative inquiry', Theory Into Practice, Vol 39, No 3, pp 124-130.

Czarniawska, B. (2004), Narratives in Social Science Research, Sage, London.

Davidsson, P., and Reynolds, P.D. (2009), 'PSED II and the comprehensive Australian study of entrepreneurial emergence [CAUSEE]', in Curtin, R.T., and Reynolds, P.D., eds, New Firm Creation in the United States: Preliminary Explorations with the PSED II Data Set, Springer, New York, pp 265-280.

Davies, B., and Harré, R. (1990), 'Positioning: the discursive production of selves', Journal for the Theory of Social Behaviour, Vol 20, No 1, pp 43-63.

De Clercq, D., and Voronov, M. (2009), 'Toward a practice perspective of entrepreneurship: entrepreneurial legitimacy as habitus', International Small Business Journal, Vol 27, No 4, pp 395-419.

Delmar, F., and Davidsson, P. (2000), 'Where do they come from? Prevalence and characteristics of nascent entrepreneurs', Entrepreneurship and Regional Development, Vol 12, No 1, pp 1-23.

Dew, N., Read, S., Sarasvathy, S.D., and Wiltbank, R. (2009), 'Effectual versus predictive logics in entrepreneurial decision-making: Differences between experts and novices', Journal of Business Venturing, Vol 24, No 4, pp 287-309.

Diochon, M., Menzies, T.V., and Gasse, Y. (2005), 'Exploring the relationship between start-up activities and new venture emergence: a longitudinal study of Canadian nascent entrepreneurs', International Journal of Management and Enterprise Development, Vol 2, No 3, pp 408-426.

Donnellon, A., Ollila, S., and Williams Middleton, K. (2014), 'Constructing entrepreneurial identity in entrepreneurship education', International Journal of Management Education, Vol 12, No 3, pp 490-499.

Down, S., and Warren, L. (2008), 'Constructing narratives of enterprise: clichés and entrepreneurial self-identity', International Journal of Entrepreneurial Behaviour and Research, Vol 14, No 1, pp 4-23.

Downing, S. (2005), 'The social construction of entrepreneurship: narrative and dramatic processes in the coproduction of organizations and identities', Entrepreneurship Theory and Practice, Vol 29, No 2, pp 185-204.

Drakopoulou Dodd, S., and Anderson, A.R. (2007), 'Mumpsimus and the mything of the individualistic entrepreneur', International Small Business Journal, Vol 25, No 4, pp 341-360.

Farmer, S.M., Yao, X., and Kung-Mcintyre, K. (2011), 'The behavioral impact of entrepreneur identity aspiration and prior entrepreneurial experience', Entrepreneurship Theory and Practice, Vol 32, No 5, pp 245-273.

Fisher, G. (2012), 'Effectuation, causation, and bricolage: a behavioral comparison of emerging theories in entrepreneurship research', Entrepreneurship Theory and Practice, Vol 36, No 5, pp 1019-1051.

Flick, U. (2006), An Introduction to Qualitative Research, Sage, London.
Franklin, S., Wright, M., and Lockett, A. (2001), 'Academic and surrogate entrepreneurs in university spinout companies', Journal of Technology Transfer, Vol 26, No 1-2, pp 127-141.

Gartner, W.B. (1988), "Who is an entrepreneur?" is the wrong question', Entrepreneurship Theory and Practice, Vol 12, No 4, pp 11-32.

Gartner, W.B. (1993), 'Words lead to deeds: towards an organizational emergence vocabulary', Journal of Business Venturing, Vol 8, No 3, pp 231-239.

Gartner, W.B., Bird, B.J., and Starr, J.A. (1992), 'Acting as if: differentiating entrepreneurial from organizational behavior', Entrepreneurship Theory and Practice, Vol 16, No 3, pp 13-31.

Gartner, W.B., Shaver, K.G., and Liao, J. (2008), 'Opportunities as attributions: categorizing strategic issues from an attributional perspective', Strategic Entrepreneurship Journal, Vol 2, No 4, pp 301-315.

Garud, R., Gehman, J., and Giuliani, A.P. (2014), 'Contextualizing entrepreneurial innovation: a narrative perspective', Research Policy, Vol 43, pp 1177-1188.

Gecas, V. (1982), 'The self-concept', Annual Review of Sociology, Vol 8, pp 1-33.

Gibb, A. (2011), 'Concepts into practice: meeting the challenge of development of entrepreneurship educators around an innovative paradigm - the case of the International Entrepreneurship Educators' Programme (IEEP)', International Journal of Entrepreneurial Behaviour and Research, Vol 17, No 2, pp 146-165.

Gibb, A.A. (2002), 'In pursuit of a new "enterprise" and "entrepreneurship" paradigm for learning: creative destruction, new values, new ways of doing things and new combinations of knowledge', International Journal of Management Reviews, Vol 4, No 3, pp 233-269.

Hamilton, E. (2011), 'Entrepreneurial learning in family business: a situated learning perspective', Journal of Small Business and Enterprise Development, Vol 8, No 1, pp 8-26.

Harrison, R.T., and Leitch, C.M. (2005), 'Entrepreneurial learning: researching the interface between learning and the entrepreneurial context', Entrepreneurship Theory and Practice, Vol 29, No 4, pp 351-371.

Haynie, J.M., Shepherd, D.A., and Patzelt, H. (2010), 'Cognitive adaptability and an entrepreneurial task: the role of metacognitive ability and feedback', Entrepreneurship Theory and Practice, Vol 36, No 2, pp 237-265.

Hytti, U. (2003), Stories of Entrepreneurs: Narrative Construction of Identities, Turku University, School of Economics and Business Administration, Turku.

Hytti, U., and Nieminen, L. (2013), 'Enacted experiences: analysing drama in entrepreneurial training', International Journal of Entrepreneurship and Innovation, Vol 14, No 2, pp 117-128.

Ibarra, H. (1999), 'Provisional selves: experimenting with image and identity in professional adaptation', Administrative Science Quarterly, Vol 44, No 4, pp 764-791.

Ibarra, H., and Barbulescu, R. (2010), 'Identity as narrative: prevalence, effectiveness and consequences of narrative identity work in macro work role transitions', Academy of Management Review, Vol 35, No 1, pp 135-154.

Johannisson, B. (2011), 'Towards a practice theory of entrepreneuring', Small Business Economics, Vol 36, No 2, pp 135-150.

Kilby, P. (1971), 'Hunting the Heffalump', in Kilby, P., ed, Entrepreneurship and Economic Development, Free Press, New York.

Lackéus, M., and Williams Middleton, K. (2015), 'Venture creation programs: bridging entrepreneurship education and technology transfer', Education + Training, Vol 57, No 1, pp 48-73.

Liao, J., and Welsch, H. (2008), 'Patterns of venture gestation process: exploring the differences between tech and 
non-tech nascent entrepreneurs', Journal of High Technology Management Research, Vol 19, No 2, pp 103-113.

Lichtenstein, B.B., Dooley, K.J., and Lumpkin, G.T. (2006), 'Measuring emergence in the dynamics of new venture creation', Journal of Business Venturing, Vol 21, No 2, pp 153-175.

Lundqvist, M.A. (2014), 'The importance of surrogate entrepreneurship for incubated Swedish technology ventures', Technovation, Vol 34, No 2, pp 93-100.

Miller, D., Le Breton-Miller, I., and Lester, R.H. (2011), 'Family and lone founder ownership and strategic behaviour: social context, identity, and institutional logics', Journal of Management Studies, Vol 48, No 1, pp 1-25.

Morris, M.H., Kuratko, D.F., Schindehutte, M., and Spivack, A.J. (2012), 'Framing the entrepreneurial experience', Entrepreneurship Theory and Practice, Vol 36, No 1, pp 11-40.

Murnieks, C.Y., and Mosakowski, E. (2007), 'Who am I? Looking inside the "entrepreneurial Identity"', Frontiers of Entrepreneurship Research, Vol 27, No 5.

Mwasalwiba, E.S. (2010), 'Entrepreneurship education: a review of its objectives, teaching methods, and impact indicators', Education + Training, Vol 52, No 1, pp 20-47.

Neck, H., and Greene, P. (2011), 'Entrepreneurship education: known worlds and new frontiers', Journal of Small Business Management, Vol 49, No 1, pp 55-70.

Nicholson, L., and Anderson, A.R. (2005), 'News and nuances of the entrepreneurial myth and metaphor: linguistic games in entrepreneurial sense-making and sense-giving', Entrepreneurship Theory and Practice, Vol 29, No 2, pp 153-172.

Nielsen, S.L., and Lassen, A.H. (2012), 'Identity in entrepreneurship effectuation theory: a supplementary framework', International Entrepreneurship and Management Journal, Vol 8, No 3, pp 373-389.

Ogbor, J. (2000), 'Mythicizing and reification in entrepreneurial discourse: ideology-critique of entrepreneurial studies', Journal of Management Studies, Vol 37, No 5, pp 605-635.

Penaluna, A., Coates, J., and Penaluna, K. (2010), 'Creativity-based assessment and neural understandings', Education + Training, Vol 52, No 8/9, pp 660-678.

Pittaway, L., and Thorpe, R. (2012), 'A framework for entrepreneurial learning: a tribute to Jason Cope', Entrepreneurship and Regional Development, Vol 24, No 9-10, pp 837-859.

Polkinghorne, D.E. (1995), 'Narrative configuration in qualitative analysis', International Journal of Qualitative Studies in Education, Vol 8, No 1, pp 5-23.

Rae, D. (2002), 'Entrepreneurial emergence: a narrative study of entrepreneurial learning in independently owned media businesses', International Journal of Entrepreneurship and Innovation, Vol 3, No 1, pp 53-59.

Rae, D. (2005), 'Entrepreneurial learning: a narrative-based conceptual model', Journal of Small Business and Enterprise Development, Vol 12, No 3, pp 323-335.

Rae, D. (2006), 'Entrepreneurial learning: a conceptual framework for technology-based enterprise', Technology Analysis and Strategic Management, Vol 18, No 1, pp 39-56.

Rae, D., and Wang, C.L. (2015), Entrepreneurial Learning: New Perspectives in Research, Education and Practice, Routledge, London.
Reynolds, P.D. (2007), 'New firm creation in the United States: a PSED I overview', Foundations and Trends in Entrepreneurship, Vol 3, No 1, pp 1-150.

Rigg, C., and O'Dwyer, B. (2012), 'Becoming an entrepreneur: researching the role of mentors in identity construction', Education + Training, Vol 54, No 4, pp 319-329.

Robb, A., and Reynolds, P.D. (2007), 'PSED II and the Kauffman firm study', in Reynolds, P.D., and Curtion, R.T., eds, New Firm Creation in the United States: Initial Explorations with the PSED II Data Set, Springer, New York.

Sarasvathy, S.D. (2008), Effectuation: Elements of Entrepreneurial Expertise, Edward Elgar, Cheltenham.

Schaffer, B.S., and Riordan, C.M. (2003), 'A review of cross-cultural methodologies for organizational research: a best-practices approach', Organizational Research Methods, Vol 6, No 2, pp 169-215.

Shani, A.B., Mohrman, S.A., Pasmore, W.A., Stymne, B., and Adler, N. (2008), Handbook of Collaborative Management Research, Sage, Thousand Oaks, CA.

Shepherd, D.A., and Haynie, J.M. (2009), 'Family business, identity conflict, and an expedited entrepreneurial process: a process of resolving identity conflict', Entrepreneurship Theory and Practice, Vol 33, No 6, pp 1245-1264.

Shepherd, D.A., Douglas, E.J., and Shanley, M. (2000), 'New venture survival: ignorance, external shocks and risk reduction strategies', Journal of Business Venturing, Vol 15, No 5-6, pp 393-410.

Tornikoski, E.T. and Newbert, S.L. (2007), 'Exploring the determinants of organizational emergence: a legitimacy perspective', Journal of Business Venturing, Vol 22, No 2, pp 311-335.

Vanevenhoven, J. (2013), 'Advances and challenges in entrepreneurship education', Journal of Small Business Management, Vol 51, No 3, pp 466-470.

Weick, K.E. (1995), Sensemaking in Organizations, Sage, Thousand Oaks, CA.

Wenger, E. (1998), Communities of Practice: Learning, Meaning, and Identity, Cambridge University Press, Cambridge.

Williams Middleton, K. (2010), 'Developing entrepreneurial behavior: facilitating nascent entrepreneurship at the university', PhD Thesis, Chalmers University of Technology, Gothenburg.

Williams Middleton, K. (2013), 'Becoming entrepreneurial: gaining legitimacy in the nascent phase', International Journal of Entrepreneurial Behaviour and Research, Vol 19, No 4, pp 404-424.

Williams Middleton, K., and Donnellon, A. (2014), 'Personalizing entrepreneurial learning: a pedagogy for facilitating the know why', Entrepreneurship Research Journal, Vol 4, No 2, pp 167-204.

Winkel, D. (2013), 'The changing face of entrepreneurship education', Journal of Small Business Management, Vol 51, No 3, pp 313-314.

Yin, R.K. (2008), Case Study Research: Design and Methods, Sage, London.

Yu, T.F.L. (2004), 'Extraordinary versus ordinary discoveries: the case of American and Chinese entrepreneurship', in Butler, J.E., ed, Opportunity Identification and Entrepreneurial Behavior, Information Age, Greenwich, CT. 